\title{
Overexpressed Transient Receptor Potential Vanilloid 3 Ion Channels in Skin Keratinocytes Modulate Pain Sensitivity via Prostaglandin $\mathrm{E}_{2}$
}

\author{
Susan M. Huang, ${ }^{1,2,3 *}$ Hyosang Lee, ${ }^{1,2,3 *}$ Man-Kyo Chung, ${ }^{1,2,3}$ Una Park, ${ }^{1,2,3}$ Yin Yin Yu, ${ }^{1,2,3}$ Heather B. Bradshaw, \\ Pierre A. Coulombe, ${ }^{1,4}$ J. Michael Walker, ${ }^{5,6^{\dagger}}$ and Michael J. Caterina ${ }^{1,2,3}$ \\ ${ }^{1}$ Department of Biological Chemistry, ${ }^{2}$ Solomon H. Snyder Department of Neuroscience, ${ }^{3}$ Center for Sensory Biology, and ${ }^{4}$ Department of Dermatology, \\ Johns Hopkins University School of Medicine, Baltimore, Maryland 21025, and ${ }^{5}$ Gill Center for Biomolecular Science and ${ }^{6}$ Department of Psychological and \\ Brain Sciences, Indiana University, Bloomington, Indiana 47405
}

The ability to sense changes in the environment is essential for survival because it permits responses such as withdrawal from noxious stimuli and regulation of body temperature. Keratinocytes, which occupy much of the skin epidermis, are situated at the interface between the external environment and the body's internal milieu, and have long been appreciated for their barrier function against external insults. The recent discovery of temperature-sensitive transient receptor potential vanilloid (TRPV) ion channels in keratinocytes has raised the possibility that these cells also actively participate in acute temperature and pain sensation. To address this notion, we generated and characterized transgenic mice that overexpress TRPV3 in epidermal keratinocytes under the control of the keratin 14 promoter. Compared with wild-type controls, keratinocytes overexpressing TRPV3 exhibited larger currents as well as augmented prostaglandin $\mathrm{E}_{2}\left(\mathrm{PGE}_{2}\right)$ release in response to two TRPV3 agonists, 2-aminoethoxydiphenyl borate (2APB) and heat. Thermal selection behavior and heat-evoked withdrawal behavior of naive mice overexpressing TRPV3 were not consistently altered. Upon selective pharmacological inhibition of TRPV1 with JNJ-7203212, however, the keratinocyte-specific TRPV3 transgenic mice showed increased escape responses to noxious heat relative to their wild-type littermates. Coadministration of the cyclooxygenase inhibitor, ibuprofen, with the TRPV1 antagonist decreased inflammatory thermal hyperalgesia in transgenic but not wild-type animals. Our results reveal a previously undescribed mechanism for keratinocyte participation in thermal pain transduction through keratinocyte TRPV3 ion channels and the intercellular messenger $\mathrm{PGE}_{2}$.

Key words: temperature; TRPV; heat; transgenic; channel; nociception

\section{Introduction}

Skin forms the interface between the internal constituents of the body and the external environment. Sensory nerve endings in the dermis and epidermis are established as cutaneous detectors of thermal, chemical, and mechanical stimuli. Keratinocytes, which

Received Dec. 28, 2007; revised 0ct. 23, 2008; accepted 0ct. 27, 2008.

This work was supported by National Institutes of Health Grants NS051551 (M.J.C.), AR44232 (P.A.C.), and DA-018244 (J.M.W.); the W. M. Keck, Searle, and Beckman Foundations (M.J.C.); the Gill Center for Biomolecular Science, Indiana University; and the Lilly Foundation, Indianapolis, IN (J.M.W.). S.M.H. is a Pfizer Fellow of the Life Sciences Research Foundation. We thank Dr. N. Carruthers and D. Swanson, Johnson \& Johnson Pharmaceutical Research and Development LLC, for providing JNJ-17203212. We thank Juan Wang for technical assistance, Jun Zhong for help with construct preparation, and Markus Delling and members of the Caterina, Coulombe, Walker, Gould, and Worley laboratories for helpful discussions. It is with deep sadness and regret that we note the loss of J. Michael Walker, Linda and Jack Gill Chair of Neuroscience and Professor at Indiana University, who died during the final preparation of this manuscript.

*S.M.H. and H.L. contributed equally to this work.

${ }^{\dagger}$ Deceased, Jan. 5, 2008.

Correspondence should be addressed to Michael J. Caterina, Department of Biological Chemistry, Solomon H. Snyder Department of Neuroscience and Center for Sensory Biology, Room 408 Biophysics Building, Johns Hopkins School of Medicine, 725 North Wolfe Street, Baltimore, MD 21205. E-mail: caterina@jhmi.edu.

M.- K. Chung's present address: Department of Neural and Pain Sciences, University of Maryland Dental School, Baltimore, MD 21201.

D01:10.1523/JNEUROSC1.5741-07.2008

Copyright $\odot 2008$ Society for Neuroscience $\quad 0270-6474 / 08 / 2813727-11 \$ 15.00 / 0$ comprise much of the epidermis, are recognized predominantly for forming a barrier against organismal invasion or loss of water and nutrients. However, the superficial location of skin keratinocytes, coupled with the close apposition of their membranes with those of sensory afferents (Hilliges et al., 1995), poise keratinocytes to communicate the presence of environmental stimuli directly to the nervous system. Whereas the release of trophic factors such as nerve growth factor (NGF) and artemin from keratinocytes can chronically modulate neuronal structure and function in the skin (Malin et al., 2006; Albers and Davis, 2007), the recent discovery of temperature sensitive ion channels of the transient receptor potential vanilloid (TRPV) family in keratinocytes has fueled the notion that keratinocytes participate in acute thermosensory transduction.

TRPV3 and TRPV4 are two thermosensitive calciumpermeable channels that are activated by heat, with thresholds of $\sim 27^{\circ} \mathrm{C}$ and $\sim 34^{\circ} \mathrm{C}$, respectively (Guler et al., 2002; Peier et al., 2002; Smith et al., 2002; Watanabe et al., 2002; Xu et al., 2002). Mice lacking either of these channels exhibit defects in thermal selection and heat-evoked withdrawal behaviors (Lee et al., 2005; Moqrich et al., 2005). TRPV3 and TRPV4 are expressed in skin keratinocytes (Guler et al., 2002; Peier et al., 2002; Xu et al., 2002), 
where these channels can be activated by heat or their respective chemical activators (Chung et al., 2003, 2004a,b; Moqrich et al., 2005; Hu et al., 2006; Xu et al., 2006). Yet, there is evidence that TRPV 3 and TRPV4 are also expressed in sensory neurons and in the CNS (Smith et al., 2002; Xu et al., 2002). Thus, the physiological significance of these channels within keratinocytes is unclear.

If keratinocytes do participate in sensory transduction, a soluble factor might be released upon stimulation of keratinocyte TRPV ion channels as a means of communication and relay. Until now, the identity of such an intercellular signaling molecule(s) has remained elusive. In this study, we generated transgenic mice overexpressing TRPV3 selectively in keratinocytes. Phenotypic analysis of these mice revealed that TRPV 3 channels expressed in keratinocytes can contribute to thermal nociception and hyperalgesia, at least in part through calcium- and cyclooxygenase-1 (COX1)-dependent release of prostaglandin $\mathrm{E}_{2}$ $\left(\mathrm{PGE}_{2}\right)$.

\section{Materials and Methods}

Chemicals. Unless otherwise indicated, chemical reagents were obtained from Sigma and cell culture reagents from Invitrogen.

Animals. The mouse TRPV3 cDNA (Chung et al., 2003) was modified to include a hemagglutinin (HA) epitope at the $\mathrm{N}$ terminus or yellow fluorescent protein (YFP, Invitrogen) at the $\mathrm{C}$ terminus. These engineered cDNAs were subcloned into the multiple cloning site of a modified keratin 14 cassette containing the keratin 14 promoter, a rabbit $\beta$-globin intron, a multiple cloning site, and the keratin 14 polyadenylation site (Paladini and Coulombe, 1998). DNA constructs were linearized and microinjected into fertilized murine $\mathrm{C} 57 \mathrm{BL} / 6 \mathrm{~J}$ oocytes, and embryos were reimplanted in the uterus of a surrogate mother. Genotypes of founders and progenies were confirmed using PCR and Southern blotting. PCR primers were $5^{\prime}$-ATCTCCAGGAAGAAGTGTGCACTC- $3^{\prime}$ and $5^{\prime}$-GGGAAGATGTCCCTTGTATCACC- $3^{\prime}$, and the size of transgenic PCR product was 705 base pairs (bp). For Southern blotting, a probe (194 bp) was generated by PCR amplification of recombinant TRPV3 with two primers; 5'-CCAAGGACAAAAAGGACTG-3' and 5'-CATCAGGGCAATGAGCAT-3', and used to detect two specific bands of $\sim 5$ kilobase pairs ( $\mathrm{kb}$, transgenic) and $\sim 2.1 \mathrm{~kb}$ (wild type) after enzymatic digestion of genomic DNA with EcoRV. Blots were scanned using a PhosphorImager. Three independent transgenic mouse lines were established. Transgenic and C57BL/6J wild-type mice were intermated to produce transgenic and wild-type experimental animals. All experiments were conducted according to protocols approved by The Johns Hopkins Animal Care and Use Committee.

Protein expression analysis. For immunoblotting, the back skin of adult wild-type or TRPV3 transgenic mice was shaved, homogenized, and then lysed using M-PER mammalian protein extraction reagent (Pierce) according to the manufacturer's instructions. Proteins were resolved by SDS-PAGE, electrotransferred to polyvinylidenedifluoride membranes, and subjected to immunoblot analysis as described (Guler et al., 2002). Primary antibodies for immunoblot included rabbit anti-TRPV3 (1:1000) (Chung et al., 2004), monoclonal mouse anti-TRPV3 (1:400, clone 15/4, University of California, Davis/National Institute of Neurological Disorders and Stroke/National Institute of Mental Health NeuroMab Facility, Davis, CA), rabbit anti-TRPV1 (1:1000, Calbiochem), rabbit anti-HA (1:1000, Covance Research Products), HRP-conjugated monoclonal rat anti-HA (1:4000, clone $3 \mathrm{~F} 10$, Roche), rabbit anti-green fluorescent protein (GFP, 1:3000, Invitrogen), mouse anti- $\beta$-actin (1: 5000, Sigma) and anti- $\alpha$-tubulin (1:10,000, Hybridomabank, University of Iowa, Iowa City, IA). Biotinylated secondary anti-rabbit and antimouse antibodies (1:5000, GE Healthcare) were used for detection by enhanced chemiluminescence (GE Healthcare). Quantification of scanned ECL films was performed using ImageJ software (National Institutes of Health). For immunofluorescence, mice were perfused transcardially with $4 \%$ paraformaldehyde/phosphate buffered saline (PBS), and the glabrous skin was dissected, cryoprotected in $30 \%$ sucrose/PBS, sectioned at $16-20 \mu \mathrm{m}$, and subjected to immunostaining as described
(Guler et al., 2002) with rabbit anti-TRPV3 (1:1000 (Chung et al., 2004), monoclonal mouse anti-TRPV3 (1:25 or 1:10, clone 15/4, NeuroMab), mouse anti-GFP (1:500, Sigma), anti-keratin 10 (1:1000, Sigma), antikeratin 14 (1:5000, Sigma), or anti-PGP 9.5 (1:1000, Ultraclone), followed by Cy3-conjugated goat anti-rabbit IgG (1:900, Jackson Immunoresearch) for rabbit primary antibodies, $\mathrm{Cy} 3$-conjugated goat antimouse IgG2a (1:500, Jackson) for monoclonal anti-TRPV3, or Cy3conjugated donkey anti-mouse (1:700, Jackson) for anti-GFP. Tissues were imaged using a Nikon E600FN epifluorescence microscope equipped with a Roper Coolsnap ES camera and ESee Software (ISee Imaging) or a Zeiss 510 Meta Scanning Confocal microscope and LSM software (Zeiss).

Cell culture. Primary mouse keratinocytes were cultured as described previously (Chung et al., 2004). Newborn mice (postnatal day 1-3) were decapitated, and their limbs were removed. After washing with betadine, water, and $70 \%$ ethanol, trunk skin was removed, stripped of fat, and floated (epidermis upward) overnight at $4^{\circ} \mathrm{C}$ in a Petri dish containing $0.25 \%$ trypsin. The epidermis was peeled from underlying tissue the following day. Keratinocytes were harvested from both surfaces of the dissection plane by flushing with medium or gentle scraping and placed in mouse keratinocyte medium (Chung et al., 2003). Cells were pelleted, resuspended in mouse keratinocyte medium, layered on a density gradient (Lymphoprep, Axis-shield), and centrifuged $\left(15 \mathrm{~min}, 500 \mathrm{rpm}, 4^{\circ} \mathrm{C}\right)$. Keratinocytes, located at the interface of the resulting two layers, were recentrifuged and resuspended, counted, plated at $10^{5} / \mathrm{cm}^{2}$ in plastic dishes or on glass coverslips, and assayed after being incubated for $40-80$ $\mathrm{h}$ at $37^{\circ} \mathrm{C} / 5 \% \mathrm{CO}_{2}$.

Electrophysiology. Whole-cell voltage-clamp analysis was performed as described previously (Chung et al., 2004). Briefly, the recording pipette was filled with internal solution containing (in mM) 120 cesium aspartate, $10 \mathrm{CsCl}, 1 \mathrm{MgCl}_{2}, 5$ EGTA, and 10 HEPES (pH 7.4, adjusted with $\mathrm{CsOH} ; 295$ mOsm, adjusted with mannitol). Osmolarity was measured using a vapor pressure osmometer (Wescor). Cells were superfused with bath solution throughout the experiment. Bath solution contained (in mM) 130 sodium aspartate, $6 \mathrm{NaCl}, 2 \mathrm{CaCl}_{2}, 1 \mathrm{MgCl}_{2}, 10$ glucose, and 10 HEPES ( $\mathrm{pH} 7.4$, adjusted with $\mathrm{NaOH} ; 305$ mOsm, adjusted with mannitol). Because of their flat morphology, cells were treated briefly with trypsin-EDTA just before whole cell recording to facilitate seal formation and membrane capacitance measurement. An Axopatch 200B amplifier (Axon Instruments) connected to a Digidata 1322A analog/digital converter (Axon) was used together with pClamp 9.0 software (Axon) to deliver voltage pulses and acquire and analyze data. Borosilicate glass electrodes had tip resistances of 1.5-2 megaohms when filled with pipette solution. We recorded whole-cell currents only when the series resistance was $<7$ megaohms without compensation. Heat stimuli were delivered using an in-line heater (Warner Instruments) and monitored with a thermocouple (Physitemp) placed within $4 \mathrm{~mm}$ of the microscopic field. Solution exchange was performed using a valve manifold (Warner Instruments).

$P G E_{2}$ measurement. Primary mouse keratinocytes were cultured from wild-type and transgenic neonatal mice as described above. Cells were plated at $10^{5} / \mathrm{cm}^{2}$ in plastic culture dishes and cultured for $48-60 \mathrm{~h}$ at $37^{\circ} \mathrm{C}, 5 \% \mathrm{CO}_{2}$ before experimentation. Cells were acclimated in buffer (in mм: $130 \mathrm{NaCl}, 3 \mathrm{KCl}, 2.5 \mathrm{CaCl}_{2}, 0.6 \mathrm{MgCl}_{2}, 10 \mathrm{Hepes}, 1.2 \mathrm{NaHCO}_{3}$ and 10 glucose, adjusted to $\mathrm{pH} 7.45$ with $\mathrm{NaOH}$ ) at room temperature for 60-90 min before experimentation. For $\mathrm{Ca}^{2+}$-free stimulation, $\mathrm{NaCl}$ was lowered to $120 \mathrm{~mm}$ and $\mathrm{CaCl}_{2}$ was replaced with $10 \mathrm{~mm}$ EGTA at $\mathrm{pH}$ 7.45. Supernatant was collected at $30 \mathrm{~min}$ intervals (baseline and stimulated conditions) unless stated otherwise. An additional antagonist pretreatment period before stimulation was included in the antagonism experiments. A circulating water bath was used for heat stimulation. Samples were spiked with 50-500 pmol $\mathrm{PGD}_{2}$-d4 (Cayman Chemicals) before processing to track endogenous $\mathrm{PGE}_{2}$ recovery. Samples were loaded onto preconditioned Bond-Elut LRC C-18 cartridges (Varian) in $50 / 50$ buffer $/ 25 \%$ methanol, washed with water, and eluted with $65 \%$ methanol. The eluant was analyzed on a Shimadzu HPLC coupled to a API-3000 triple quadrupole MS (Applied Biosystems) with the following conditions: linear gradient from $17-100 \%$ methanol/water with $1 \mathrm{~mm}$ ammonium acetate at $0.2 \mathrm{ml} / \mathrm{min}$ over $3 \mathrm{~min}$, XDB-C18 HPLC column 
(3.5 $\mu \mathrm{m}, 2.5 \mathrm{~mm} \times 50 \mathrm{~mm}$; Agilent Technologies), electrospray negative ion multiple reaction monitoring mode (Q1-Q3 = 351.2-315.1, 359.3315.4). Standard curves were constructed for each batch of analysis, and the levels of analytes in the samples were extrapolated accordingly. The amount of $\mathrm{PGE}_{2}$ was corrected for recovery and protein content (BCA assay, Pierce) in each culture well.

Temperature selection assay. Temperature selection assays were performed as described previously (Lee et al., 2005). Briefly, a mouse was placed on a $170 \mathrm{~cm} \times 10 \mathrm{~cm}$ metal platform on which a linear thermal gradient spanning from 0.8 to $48.8^{\circ} \mathrm{C}$ was maintained in the long axis by means of feedback-controlled resistive heaters and a heat sink. The position of the mouse within the surface temperature gradient was then monitored over a $2 \mathrm{~h}$ test period using a series of infrared beams and activity monitoring software (OptoMax, Columbus Instruments). Wildtype and transgenic mice were alternated to minimize the impact of any nonthermal variables.

Assays of acute nociception and hyperalgesia. In the tail immersion assay, the tail of a gently restrained mouse was immersed in a water bath set at $46-50^{\circ} \mathrm{C}$, and the time to tail withdrawal was recorded. In the radiant paw heating assay, the plantar surface of one hindpaw of a mouse standing on a glass surface was subjected to radiant heat stimulation and the latency to paw withdrawal was measured. In the hot plate assay, a freely moving mouse was placed on a metal surface preheated to $46-52^{\circ} \mathrm{C}$ and latency to the onset of biting, licking or rapid shaking of the hindpaws was measured. To induce peripheral inflammation, $15 \mu \mathrm{l}$ of Complete Freund's adjuvant (CFA) (Sigma) was injected subcutaneously into the plantar surface of one hindpaw using a Hamilton (Hamilton) syringe and a 30 gauge needle. With the exception of the temperature preference assay, which was scored automatically, all behavioral assays were performed with the experimenter blinded to genotype or treatment.

Behavioral assays with JNJ-7203212 and ibuprofen. Following 4 baseline latency measurements in the hot plate test $\left(52^{\circ} \mathrm{C}\right)$, animals were injected intraperitoneally with $40 \mathrm{mg} / \mathrm{kg}$ ibuprofen or vehicle (PBS) and 40 mg/kg JNJ-7203212 (Ghilardi et al., 2005; Swanson et al., 2005) (Johnson \& Johnson, Pharmaceutical Research and Development LLC) or vehicle (1:4:15 Pharmasolv: Cremaphor: 5\% Dextrose), prewarmed to $37^{\circ} \mathrm{C}$. Responses to the hot plate were tested at $30 \mathrm{~min}$ intervals following injection. For the inflammatory pain paradigm, baseline paw withdrawal latencies to a radiant heat source were established before injection of CFA in the left hindpaw ( $15 \mu \mathrm{l}$, intraplantar), and post-CFA withdrawal latencies recorded $24 \mathrm{~h}$ following CFA injection. Upon establishment of post-CFA baseline, $40 \mathrm{mg} / \mathrm{kg}$ ibuprofen or vehicle was injected intraperitoneally and $15 \mathrm{~min}$ later, $40 \mathrm{mg} / \mathrm{kg} \mathrm{JNJ}-7203212$ or vehicle were injected intraperitoneally (all prewarmed to $37^{\circ} \mathrm{C}$ ) and paw withdrawal latencies monitored at $20 \mathrm{~min}$ intervals thereafter.

Core body temperature measurements. Mice were surgically implanted with telemetric body temperature probes (G2 E-Mitter, Minimitter) in their peritoneal cavity as previously described (Lee et al., 2005). Mice were allowed to recover for at least $7 \mathrm{~d}$ until normal circadian rhythm of core body temperature was re-established. Using telemetric receiver platforms (ER-4000, Minimitter) and VitalView software (Minimitter), core body temperature was continuously monitored at $2 \mathrm{~min}$ intervals with the mice freely moving in their home cages. Mice were handled daily for $2 \mathrm{~d}$ before drug challenge. On the testing day, after a $30 \mathrm{~min}$ baseline period, mice were injected intraperitoneally with $40 \mathrm{mg} / \mathrm{kg}$ JNJ-7203212 or vehicle (prewarmed to $37^{\circ} \mathrm{C}$ ) as for thermal nociception assays, and body temperature monitored in the absence of experimenters for $24 \mathrm{~h}$.

Statistical analyses. Data are expressed as mean \pm SEM. Data from the $\mathrm{PGE}_{2}$ release experiments were analyzed using ANOVA with Bonferroni or Dunnett's post hoc comparisons. Electrophysiology data were analyzed using ANOVA with Bonferroni post hoc comparisons. Data from behavioral experiments were evaluated using the Mann-Whitney $U$ test, ANOVA with repeated measures with Bonferroni post hoc comparisons, or two-tailed $t$ tests for experiments with planned comparison designs. Statistical analyses were performed using either Microsoft Excel or Prism (GraphPad).

\section{Results \\ Keratinocyte-specific overexpression of TRPV3 in transgenic mice}

To study the role of TRPV3 in keratinocytes, we generated transgenic mice overexpressing TRPV3 tagged with either YFP at its $\mathrm{C}$ terminus or an HA epitope at its $\mathrm{N}$ terminus under the control of the keratin 14 promoter, which drives gene expression in most basal cells of stratified squamous epithelia including the skin epidermis (Fig. $1 A$ ). Two transgenic lines (A and B) were established with the HA-TRPV 3 construct, and one line was established with the TRPV3-YFP construct. Transgenic mice of all three lines exhibited no obvious abnormalities in behavior or in the appearance of their skin and hair as neonates or young adults. Genomic incorporation of the transgenes was verified by Southern blot (Fig. $1 B$ ). The number of transgene copies per genome (transgene/endogenous) was $11.2 \pm 1.7$ for TRPV3-YFP $(n=6), 4.4 \pm$ 0.4 for HA-TRPV3 (B) $(n=26)$ and $1.9 \pm 0.3$ for HA-TRPV3 (A) $(n=14)$. Transgenic protein expression was detected in lysates of back skin from adult transgenic animals, using either antiTRPV3 (Fig. 1C,G), anti-HA (Fig. $1 D$ ) or anti-GFP antibodies (Fig. $1 E, G$ ). HA-TRPV3 migrated at $\sim 90-100 \mathrm{kDa}$ and TRPV3YFP at $\sim 115 \mathrm{kDa}$ (Fig. $1 C-G$ ). A less intense band with the same mobility as recombinant mouse TRPV3 was detected in wild-type skin using anti-TRPV3 (Fig. 1C). Similar results were obtained using two additional anti-TRPV3 antibodies (data not shown). Although absolute transgenic protein expression levels varied among preparations, the rank order of TRPV3 protein expression (endogenous and transgenic) in adult back skin of the different lines was TRPV3-YFP > HA-TRPV3 (B) > HA-TRPV3 (A) > wild-type, with an approximate ratio of 18:8:4:1. A lesser extent of transgenic protein overexpression was apparent in primary keratinocyte cultures (Fig. 1F). Consistent with these findings, reverse transcription-PCR (RT-PCR) analysis revealed an increase in TRPV3 mRNA in the back skin of all three transgenic mouse lines, compared with wild-type (supplemental Fig. S1 A, available at www.jneurosci.org as supplemental material). Together, these results indicate that all three lines of transgenic mice overexpress TRPV3 in keratinocytes.

No transgenic protein was detected in lysates of trigeminal ganglia of the HA-TRPV3 (A) or TRPV3-YFP lines, although trace amounts were detected in the HA-TRPV3 (B) line using anti-HA (Fig. $1 G$ ) (data not shown). mRNA encoding transgenic TRPV3 was detected in the trigeminal ganglia of HA-TRPV3 lines (A) and (B), but not in TRPV3-YFP trigeminal ganglia (supplemental Fig. S1 A, available at www.jneurosci.org as supplemental material). The amount of TRPV1 protein in the trigeminal ganglia was comparable between wild-type and TRPV3-YFP transgenic animals (supplemental Fig. S1B, available at www. jneurosci.org as supplemental material). The amount of TRPV4 mRNA in back skin and trigeminal ganglia was also comparable between wild-type mice and mice of all three transgenic lines (supplemental Fig. S1 A, available at www.jneurosci.org as supplemental material), arguing against the occurrence of compensatory changes in the expression levels of these homologous thermosensory proteins.

Localization of transgenic TRPV3 was visualized by immunofluorescence using anti-TRPV3 antibodies. In glabrous hindpaw skin of wild-type animals, modest TRPV3-like immunoreactivity was observed, with enrichment in the lower portion of the epidermis (Fig. 2A; supplemental Fig. S2A,B, available at www. jneurosci.org as supplemental material). In contrast, stronger TRPV3 immunoreactivity was consistently observed in the epi- 


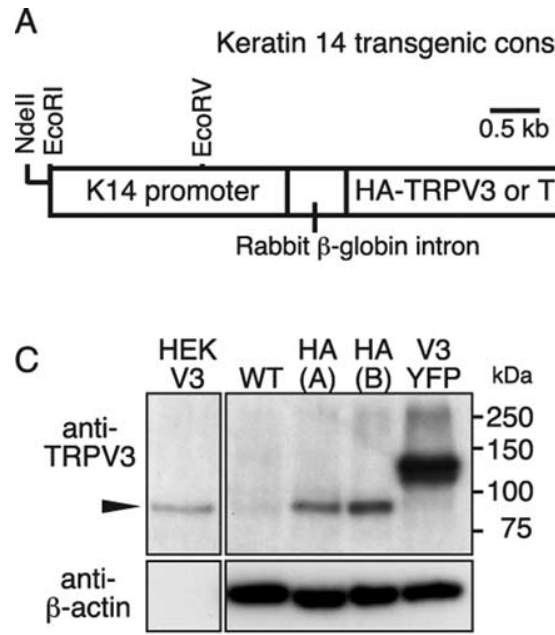

$\mathrm{F}$

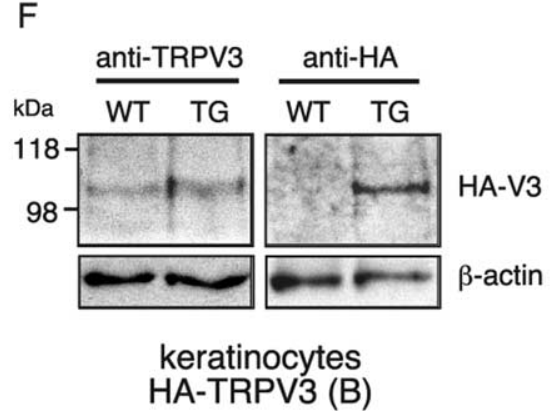

D
B HA-V3 (A) $\mathrm{HA-V3}(\mathrm{B})$
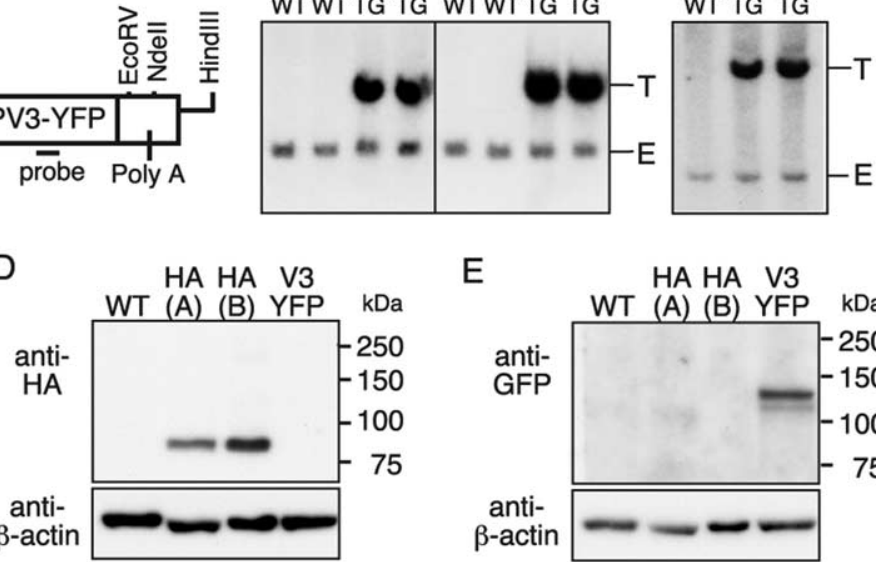

$\mathrm{E}$

HA HA V3

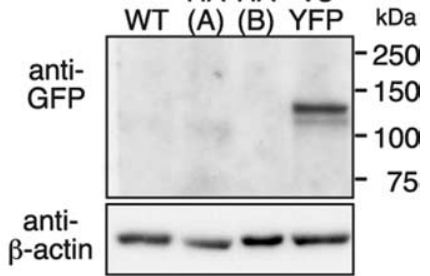

G

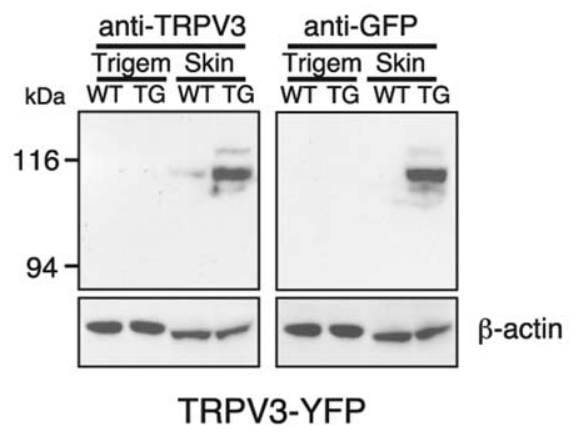

Figure 1. Generation of keratinocyte-specific TRPV3-overexpressing transgenic mice. A, Keratin 14 promoter driven TRPV3 transgenic constructs. $B$, Southern blots of EcoRV-digested genomic DNA, using the probe indicated in panel $A$, confirming genomic incorporation of the transgene in 3 lines of transgenic mice (HA-TRPV3 A, HA-TRPV3 B, TRPV3-YFP). T, Transgenic band; E, endogenous band. $\mathbf{C}-\boldsymbol{E}$, Immunoblot comparison of TRPV3 expression in the back skin of adult wild-type mice versus mice from HA-TRPV3 and TRPV3-YFP lines. Blots were probed with mouse monoclonal anti-TRPV3 (C), rat monoclonal anti-HA (D), and rabbit anti-GFP (E). Lane at far left in ( shows lysate from HEK293 cells transiently transfected with recombinant TRPV3, whose position is denoted by arrowhead. $\boldsymbol{F}$, Immunoblots probed with rabbit anti-TRPV3 and rabbit anti-HA antibodies, showing increased transgenic protein expression in cultured HA-TRPV3 B keratinocytes. $\mathbf{G}$, Immunoblots showing increased transgenic protein expression in the skin but not in trigeminal ganglia of TRPV3-YFP mice using rabbit anti-TRPV3 and rabbit anti-GFP antibodies.

dermis of transgenic mice, although the precise pattern and intensity of expression differed between lines. HA-TRPV3 (A) skin exhibited basal epidermal TRPV3 immunoreactivity indistinguishable from that of wild-type skin, but strong immunoreactivity in a few scattered suprabasal keratinocytes (Fig. 2B). Skin from HA-TRPV3 (B) mice exhibited even more frequent robust staining of suprabasal keratinocyte patches, as well as occasionally increased staining in the basal epidermis (Fig. 2C). In the TRPV3-YFP line, robust TRPV3 immunoreactivity was uniformly observed among basal keratinocytes (Fig. $2 D$ ), a pattern overlapping that of endogenous TRPV3-like immunoreactivity and recapitulating keratin 14 expression (supplemental Fig. S2 E, F, available at www.jneurosci.org as supplemental material). A few scattered suprabasal keratinocytes also showed strong antiTRPV3 staining in TRPV3-YFP transgenic mice. Similar patterns of transgenic protein expression among the three lines were observed using two additional anti-TRPV3 antibodies (data not shown). The pattern of transgene expression in TRPV3-YFP transgenic mice was further corroborated by the intrinsic fluorescence of the TRPV3-YFP fusion protein (Fig. 2E,F) and by staining with an anti-GFP antibody (supplemental Fig. $S 2 C, D$, available at www.jneurosci.org as supplemental material). No transgenic protein expression was detected in sensory ganglia of any line by immunofluorescence using anti-HA or anti-GFP antibodies (data not shown). To determine whether overexpression of TRPV3 altered keratinocyte differentiation or epidermal innervation, we immunostained the glabrous hindpaw skin of wild- type and TRPV3-YFP transgenic mice with anti-keratin 14 (labels basal keratinocytes), anti-keratin 10 (labels suprabasal keratinocytes) and anti-PGP 9.5 (labels sensory nerve fibers). No obvious differences in staining pattern were observed between wild-type and transgenic mice for any of these three markers (supplemental Fig. S2E-J, available at www.jneurosci.org as supplemental material).

\section{Increased channel function in}

TRPV3-overexpressing keratinocytes

To evaluate the functional consequences of increased TRPV3 expression, we performed whole-cell patch-clamp electrophysiology on primary keratinocytes cultured from neonatal mice. Consistent with our previously reported findings (Chung et al., $2004 \mathrm{a}, \mathrm{b})$, heat stimuli $\left(40-43^{\circ} \mathrm{C}, 30 \mathrm{~s}\right)$ evoked small, outwardly rectifying current responses in $\sim 80 \%$ of wild-type keratinocytes (Fig. $3 A, C$ ). These responses desensitized upon repetitive applications of heat, consistent with mediation by endogenous TRPV4 (Chung et al., 2004). The TRPV3 agonist 2-aminoethoxydiphenyl borate (2APB, $100 \mu \mathrm{M}$ ) (Chung et al., 2004b; Hu et al., 2004) evoked little response in wild-type keratinocytes when added alone (Fig. $3 B, D)$. However, the coapplication of $2 \mathrm{APB}$ and heat yielded larger current responses that sensitized with repetitive stimulation, characteristic of those mediated by endogenous TRPV3 (Fig. 3 B,D) (Chung et al., 2004b; Moqrich et al., 2005). Examination of keratinocytes isolated from TRPV3 transgenic mice revealed a continuum of increased responsiveness to TRPV3 ago- 

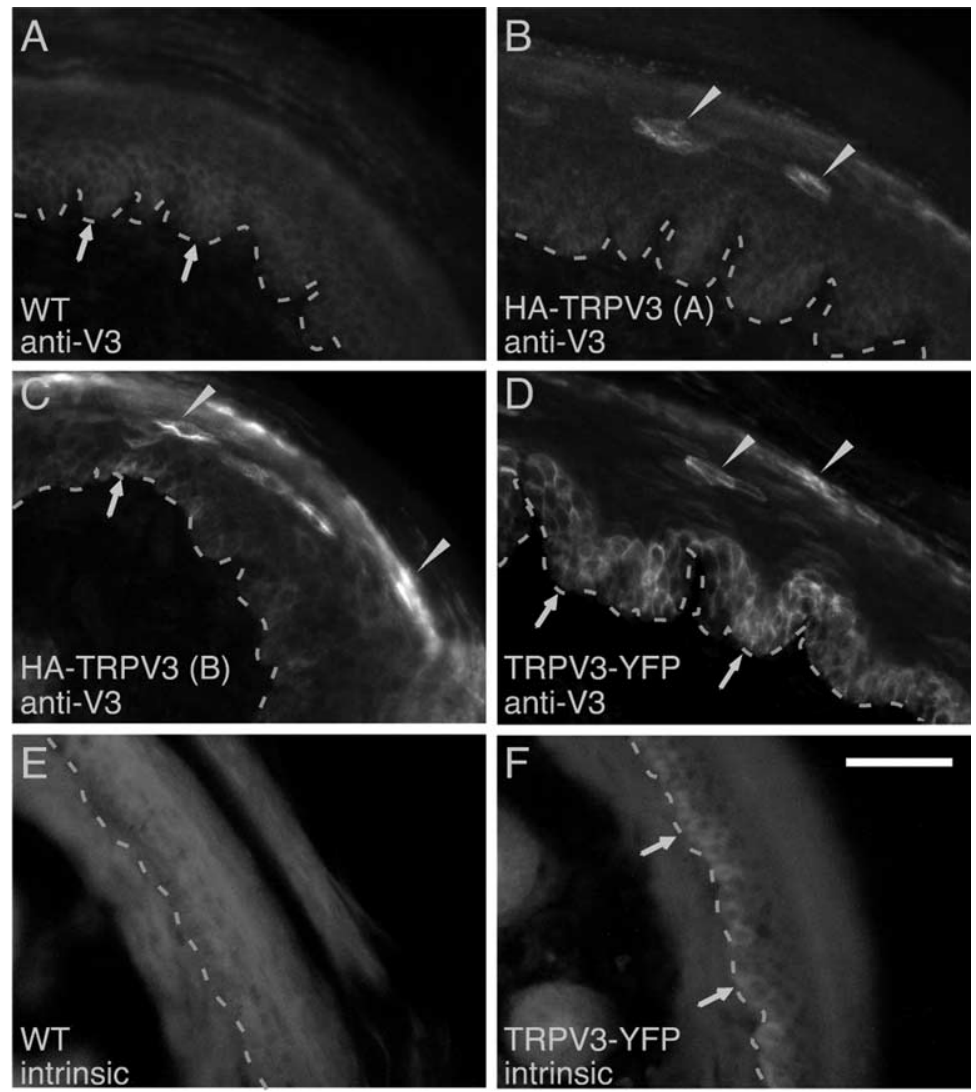

Figure 2. Immunofluorescent localization of TRPV3 in skin of transgenic mice. $\boldsymbol{A}-\boldsymbol{D}$, Hindpaw glabrous skin of wild-type $(\boldsymbol{A})$, HA-TRPV3 A (B), HA-TRPV3 B (C), or TRPV3-YFP $(\boldsymbol{D})$ mice, respectively, probed with anti-TRPV3. Increased TRPV3 staining was observed in the skin epidermis of transgenic mice. $\boldsymbol{E}, \boldsymbol{F}$, Intrinsic YFP fluorescence in wild-type $(\boldsymbol{E})$ and TRPV3-YFP transgenic $(\boldsymbol{F})$ skin. Dashed line denotes dermal-epidermal junction. Arrows mark basal epidermal staining, arrowheads mark suprabasal epidermal staining. Scale bar, $50 \mu \mathrm{m}$.

nists. Whereas repetitive heat stimuli evoked only minute currents in cells of the HA-TRPV3 (A) line, progressively larger responses were observed in cells derived from lines HA-TRPV3 (B) ( $p<0.001$ vs wild-type at $+80 \mathrm{mV}$, repeated measures two-way ANOVA) and TRPV3-YFP ( $p<0.01$ vs wild-type at $+80 \mathrm{mV})$, respectively, which also sensitized with repetitive stimulation (Fig. $3 A, B$ ). Moreover, in a subset of TRPV3-YFP keratinocytes, persistent stimulation with heat produced a biphasic current, the second component of which was characterized by large amplitude and loss of outward rectification (supplemental Fig. S3 A, B, available at www.jneurosci.org as supplemental material). We previously reported that the appearance of such biphasic responses is highly dependent on TRPV3 current density (Chung et al., 2005). A progression of increasing current amplitudes among the 3 transgenic lines was also observed during stimulation with 2APB alone $(p<0.0001$ at $+80 \mathrm{mV}, p<0.05$ at $-80 \mathrm{mV}$, one-way ANOVA with Bonferroni post hoc comparison) (Fig. $3 D)$. As in wild-type keratinocytes, coapplication of heat and 2APB resulted in much larger currents in both HA-TRPV3 lines than were seen with either stimulus alone (Fig. $3 B, D$ ). Thus, transgenic overexpression of TRPV3 results in graded electrophysiological responses that are proportional to relative channel expression levels in the different transgenic lines.

Keratinocyte TRPV3 activation leads to the release of $\mathrm{PGE}_{2}$ To understand how TRPV3 ion channels in keratinocytes might mediate downstream effects, we searched for a factor that could be acutely released from keratinocytes in response to TRPV3 activation and is known to influence sensory neurons. One such candidate mediator is $\mathrm{PGE}_{2}$, which was previously shown to be released from keratinocytes in response to several nonthermal stimuli, and can promote thermal and mechanical hypersensitivity by acting through G-protein-coupled EP receptors on sensory neurons (Ferreira et al., 1978; Taiwo and Levine, 1989a,b; Sugimoto et al., 1994; Oida et al., 1995; Southall and Vasko, 2001; Moriyama et al., 2005), or serve as a precursor for pronociceptive agonists of TRPA1 (Materazzi et al., 2008). We therefore assayed the release of $\mathrm{PGE}_{2}$ from keratinocytes cultured from wildtype and transgenic neonatal mice. Using liquid chromatography-tandem mass spectrometry (LC-MS/MS), we could readily detect $\mathrm{PGE}_{2}$ release under basal conditions from keratinocytes of both genotypes (Fig. $4 A$, inset). Upon exposure to 2APB (50 or $100 \mu \mathrm{M}$ ), however, TRPV3YFP transgenic keratinocytes released $\sim 7$ fold more $\mathrm{PGE}_{2}$, compared with wild-type cells (Fig. 4A) $(p<0.001)$. The effect was unlikely to be due to generalized hyperresponsiveness of the transgenic cells, since no differences in evoked $\mathrm{PGE}_{2}$ levels were seen when cells were stimulated with the calcium ionophore A23187 ( $1 \mu \mathrm{M})$ (Fig. 4A). Another TRPV3 chemical agonist, camphor (Moqrich et al., 2005), also increased $\mathrm{PGE}_{2}$ from TRPV3-YFP keratinocytes $(2.91 \mathrm{pmol} / \mathrm{mg}$ protein at $2 \mathrm{~mm}$ camphor; $10.8 \mathrm{pmol} / \mathrm{mg}$ protein at $4 \mathrm{~mm}$ camphor) compared with wild-type keratinocytes $(1.14 \mathrm{pmol} / \mathrm{mg}$ protein at $2 \mathrm{mM}$ camphor, $p<0.05 ; 3.65 \mathrm{pmol} / \mathrm{mg}$ protein at $4 \mathrm{~mm}$ camphor, $p<$ $0.001 ; n=3$ wells per group). It has previously been reported that the TRPV1-selective agonist, capsaicin, evokes $\mathrm{PGE}_{2}$ release in the human keratinocyte-derived HaCaT cell line (Southall et al., 2003). However, we did not observe capsaicin (1-10 $\mu \mathrm{M})$-evoked $\mathrm{PGE}_{2}$ release from mouse primary wild-type keratinocytes (data not shown), consistent with our previous electrophysiological and immunoblot findings (Chung et al., 2004). In addition to chemical agonists, we tested the effect of sustained heat stimuli on keratinocyte $\mathrm{PGE}_{2}$ release. Wild-type keratinocytes exhibited a temperature-dependent increase in $\mathrm{PGE}_{2}$ release that peaked at $42^{\circ} \mathrm{C}$ and declined slightly at higher temperatures (Fig. $4 \mathrm{~B}$ ). In TRPV3-YFP transgenic keratinocytes, heat evoked $\mathrm{PGE}_{2}$ release was significantly greater than in wild-type keratinocytes at $42^{\circ} \mathrm{C}$ $(p<0.01)$, with a strong trend toward increased responses at all temperatures $>31^{\circ} \mathrm{C}$, reminiscent of the temperaturedependence of TRPV3. These data are consistent with TRPV3mediated heat-evoked $\mathrm{PGE}_{2}$ release. HA-TRPV3 (B) keratinocytes also exhibited increased 2APB-evoked $\mathrm{PGE}_{2}$ release compared with wild-type. As with TRPV3-mediated current responses, exposure of HA-TRPV3 (B) transgenic keratinocytes to a combination of $2 \mathrm{APB}(100 \mu \mathrm{M})$ and modest heat $\left(36^{\circ} \mathrm{C}\right.$ ) caused a supra-additive increase in $\mathrm{PGE}_{2}$ release (Fig. $4 C)(p<0.001)$. No such supra-additivity was observed in wild-type keratinocytes. 
A more detailed examination revealed that the augmented $\mathrm{PGE}_{2}$ release from HA-TRPV3 (B) transgenic keratinocytes was evident as early as $1-5 \mathrm{~min}$ from the onset of stimulation, indicating that the mechanisms underlying this response could be engaged rapidly (Fig. 4D). Since our assay required the accumulation of $\mathrm{PGE}_{2}$ in bulk medium, the true kinetics of the release response might be even more rapid. Removal of extracellular calcium abolished the TRPV3-dependent release of $\mathrm{PGE}_{2}$ (Fig. $\left.4 E\right)(p<0.01)$. Coapplication of the nonselective COX inhibitor ibuprofen $(100 \mu \mathrm{M})$ blocked the stimulated response, as did the COX-1 selective inhibitor SC-560 $(1 \mu \mathrm{M})$. In contrast, the COX-2 selective inhibitor CAY10404 $(10 \mu \mathrm{M})$ had only a modest inhibitory effect (Fig. $4 E$ ) $(p<0.01)$. Therefore, the rapid release of $\mathrm{PGE}_{2}$ following activation of TRPV3 receptors on keratinocytes is dependent upon calcium influx and the COX-1 enzyme.

\section{Keratinocyte TRPV3 modulates pain behaviors via prostaglandin action} Because TRPV3 channels are activated by non-noxious heat stimuli and selection of preferred floor temperature is reportedly delayed in TRPV3 knock-out mice (Moqrich et al., 2005), we tested the possibility that overexpression of TRPV3 in keratinocytes might affect perception of innocuous temperatures. We observed no consistent significant differences in any of our three transgenic lines, compared with wild-type littermates, in either the distribution of their final locations on a continuous floor gradient of $0-49^{\circ} \mathrm{C}$ or in their rates of assuming that distribution (Fig. 5A; supplemental Figure $\mathrm{S} 4 A, B$, available at www.jneurosci.org as supplemental material) (data not shown). Thus, overexpression of keratinocyte TRPV3 does not appear to influence thermal selection behavior. We also observed no differences in daytime rectal temperature between wild type and HA-TRPV3 (A) transgenic mice (wild type, $36.0 \pm$ $0.2^{\circ} \mathrm{C}, n=11$; transgenic $36.0 \pm 0.1^{\circ} \mathrm{C}, n=14$ ).

Since studies of TRPV 3 knock-out mice implicated this channel in behavioral responsiveness to acute painful heat stimuli (Moqrich et al., 2005), we also performed assays of thermal nociception on our transgenic mice. Wild-type and TRPV3overexpressing mice exhibited similar escape latencies in the tail immersion assay (over the range of $46-50^{\circ} \mathrm{C}$ ) (Fig. $5 \mathrm{~B}$ ) and in the radiant paw heating assay (Fig. $5 C$ ). In contrast, in the hot-plate assay, 2 of 3 independent cohorts of HA-TRPV3 (B) mice showed significantly shorter withdrawal latencies at 47 and $48^{\circ} \mathrm{C}$, and 1 of 2 cohorts of HA-TRPV3 (A) mice showed significantly shorter latencies at 46 and $47^{\circ} \mathrm{C}$, compared with wild-type littermates (Fig. 5D; supplemental Fig. S4C, available at www.jneurosci.org as supplemental material) $(n=9-13$ mice per genotype in each cohort). However, no significant differences from wild-type were found in either of two cohorts of the TRPV3-YFP line (Fig. 5D; supplemental Fig. S4C, available at www.jneurosci.org as supple-
B

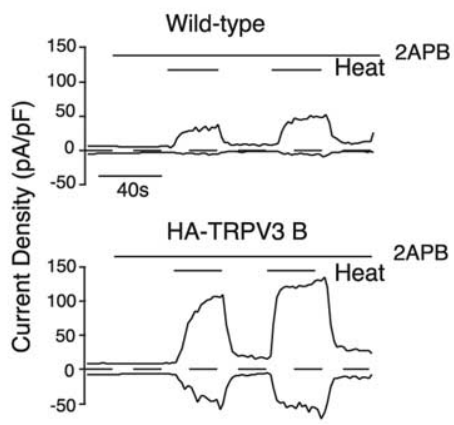

D
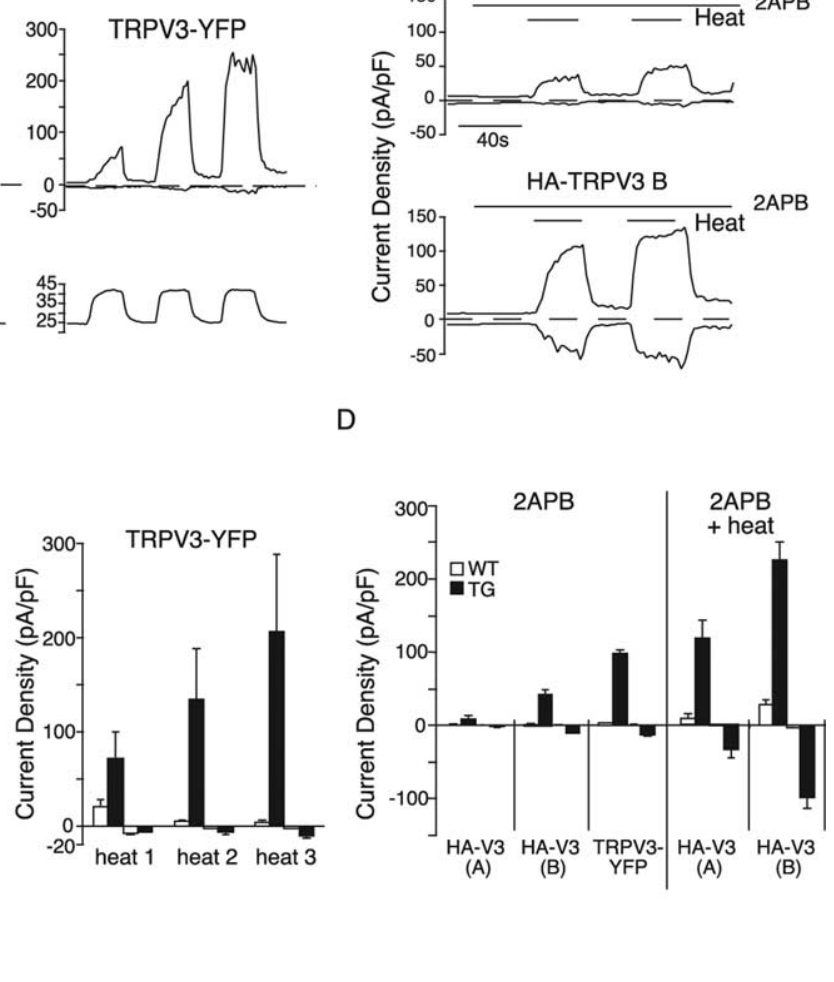

Whole-cell patch-clamp electrophysiology of primary keratinocytes from TRPV 3 transgenic mice. $A$, Representative (t) was applied in the middle of the response to $2 A P B$, as indicated by the horizontal bars. C, Quantification of onses at $-80 \mathrm{mV}$. Open bars represents the wild-type response and the filled bars represent the response of the

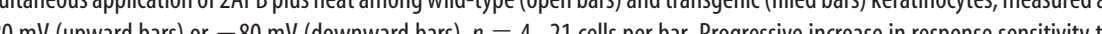
TRPV3 agonists was observed in the order of wild-type $<$ HA-TRPV3 A $<$ HA-TRPV3 B $<$ TRPV3-YFP.

mental material) ( $n=7-13$ mice per genotype in each cohort), despite the fact that this line expresses the highest level of transgenic TRPV3. Hence, two of the three keratinocyte-specific TRPV3 lines showed increased sensitivity to moderately hot stimuli, albeit inconsistently. We also evaluated hyperalgesia in TRPV3-YFP transgenic mice following inflammation evoked by hindpaw injection of CFA. No significant differences in thermal (radiant heat) hypersensitivity were observed between transgenic and wild-type animals (Fig. 5C).

The modest and inconsistent thermal nociception phenotypes of our TRPV 3 transgenic mice led us to consider the possibility that other thermosensitive molecules might be masking the contribution of TRPV3. TRPV1 has been shown to be important for both acute thermal nociception and inflammatory thermal hyperalgesia in mice (Caterina et al., 2000; Davis et al., 2000; GarciaMartinez et al., 2002; Gavva et al., 2005; McGaraughty et al., 2006). We therefore examined the effects of acute administration of a TRPV1-selective antagonist, JNJ-7203212 (Ghilardi et al., 2005; Swanson et al., 2005) on thermal nociception in wild-type and TRPV3 transgenic mice. Using HEK293 cells stably transfected with either rat TRPV1 (Guler et al., 2002) or mouse TRPV3-YFP (Chung et al., 2005), we first confirmed the ability of JNJ-7203212 (200 nM) to inhibit TRPV1 activation and its lack of 
A

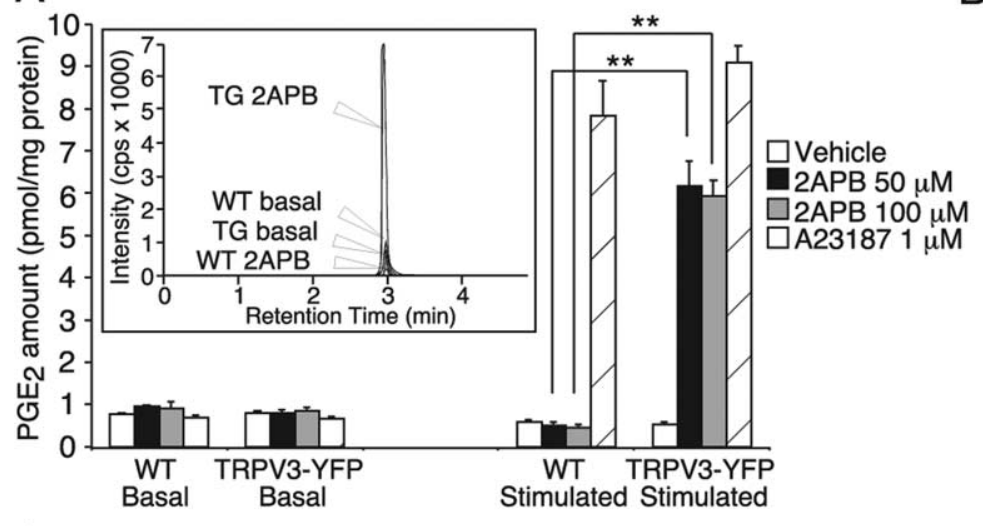

C

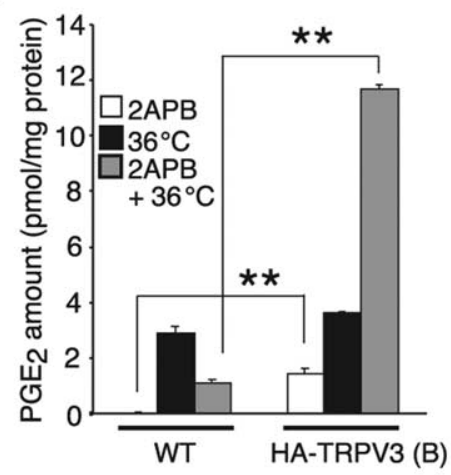

B

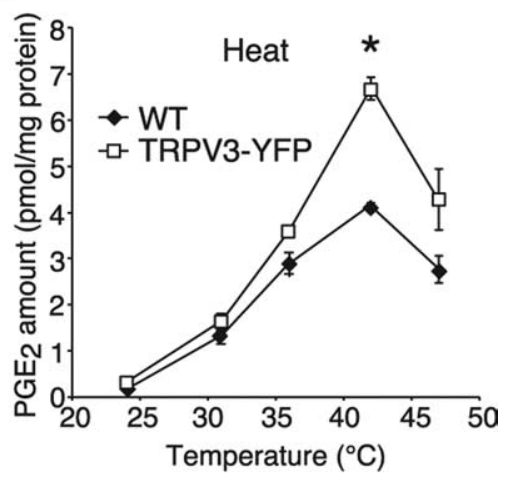

$\mathrm{E}$

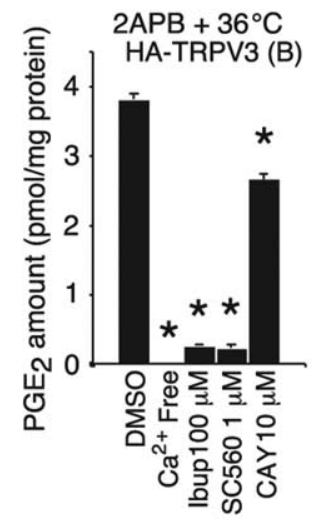

Figure 4. Measurement of $\mathrm{PGE}_{2}$ release from primary keratinocytes. Supernatants from cultured keratinocytes in buffer were collected during baseline and stimulus periods ( 30 min each), and processed and analyzed for $\mathrm{PGE}_{2}$ using LC-MS/MS. A, TRPV3-YFP transgenic keratinocytes show increased PGE 2 release compared with wild-type keratinocytes in response to the TRPV3 agonist 2 APB (50-100 $\mu \mathrm{M})$, but comparable responses to A23187 (1 $\mu \mathrm{M})$. Inset, Example chromatograms showing detection of PGE $\mathrm{E}_{2}$ from buffer under basal and stimulated conditions using LC-MS/MS. $\boldsymbol{B}$, Exposure to heat (by immersion in a water bath) increased PGE $E_{2}$ release in TRPV3-YFP transgenic keratinocytes more than in wild type. C, Supra-additive increase in stimulated PGE, release in HA-TRPV3 line B compared with wild-type keratinocytes in response to coapplication of $2 \mathrm{APB}(100 \mu \mathrm{m})$ and $36^{\circ}$ C. $D$, Cumulative stimulated PGE 2 release over time (buffer collected after 1,5, 10 or 30 min incubation) in wild-type and HA-TRPV3 line B keratinocytes. E, $2 A P B(100 \mu \mathrm{m})$ plus $36^{\circ} \mathrm{C}$-stimulated PGE, release in HA-TRPV3 line B keratinocytes is diminished in calcium-free buffer and in the presence of COX antagonists. Data are expressed as mean $\pm \mathrm{SEM}, n=3$ per group. $\boldsymbol{A}-\boldsymbol{D}$ were analyzed using ANOVA with Bonferroni post hoc comparisons and $\boldsymbol{E}$ was analyzed using ANOVA with Dunnett's test. ${ }^{* *} p<0.001,{ }^{*} p<0.01$, difference between wild type and transgenic $(\boldsymbol{A}-\boldsymbol{D})$ or between pharmacological treatment and vehicle (DMSO) control in cells treated with $2 \mathrm{APB}$ plus heat $(\boldsymbol{E})$.

effect on TRPV3 at a five-fold higher concentration (supplemental Fig. S3C-E, available at www.jneurosci.org as supplemental material). In the hot plate assay $\left(52^{\circ} \mathrm{C}\right), \mathrm{JNJ}-7203212(40 \mathrm{mg} / \mathrm{kg}$, i.p.) significantly increased escape latencies in wild-type mice, a finding consistent with previous reports that pharmacological TRPV1 antagonism can suppress acute thermal nociception (McGaraughty et al., 2006). Although the TRPV1 antagonist also increased hot plate latencies in TRPV3-YFP transgenic mice, it did so to a lesser extent, resulting in significantly shorter escape latencies compared with those of their wild-type littermates (Fig. $6 A$ ) (ANOVA with repeated measures, $p<0.05$ ). Thus, in the naive state, TRPV1 appears to mask the pronociceptive effects of keratinocyte TRPV3 overexpression. To determine if $\mathrm{PGE}_{2}$ contributes to the relay of thermosensory information from TRPV3expressing keratinocytes to sensory neurons, we performed the hot plate test in the presence of JNJ-7203212 as described above, with or without pretreatment with the COX antagonist ibuprofen (40 mg/kg, i.p.). In the absence of ibuprofen, TRPV3-YFP transgenic mice exhibited shorter escape latencies compared with their wild-type littermates (Fig. $6 B)(p<0.05)$, confirming the findings of the experiment shown in Figure $6 \mathrm{~A}$. Administration of ibuprofen resulted in tendencies toward shorter latencies in wildtype mice and longer latencies in TRPV3 transgenic mice. Although those trends did not reach statistical significance, the hy- persensitivity of TRPV3 transgenic mice was eliminated as a result (Fig. 6B).

Because TRPV1 contributes more to inflammatory thermal hyperalgesia than to acute thermal nociception (Caterina et al., 2000; Davis et al., 2000), we next asked whether TRPV1 antagonism would unmask any differences between wild-type and TRPV3 transgenic mice under inflammatory conditions. Twenty-four hours after inflammation evoked by CFA (same experiment as shown in Fig. 5C), the TRPV1 antagonist substantially increased latencies of paw withdrawal from radiant heat in wild-type mice, as well as in TRPV3-YFP transgenic mice (Fig. $6 C$ ). As in the acute hot plate assay, there was a tendency toward shorter latencies in the transgenic mice, but in this case, the difference was not statistically significant. Following CFA inflammation, in the presence of the TRPV1 antagonist, ibuprofen did not alter the withdrawal latency of inflamed wild-type mice. In contrast, ibuprofen significantly increased the response latency of the TRPV3 overexpressing mice, indicating a greater contribution of prostaglandins to thermal hyperalgesia in the transgenic animals (Fig. 6C) $(p<0.05)$. Together, these findings support the notion that thermal pain sensitivity can be modulated by prostaglandin signaling downstream of keratinocyte TRPV3.

Among the recently recognized consequences of acute TRPV1 antagonism is a transient hyperthermia that has been reported 
A
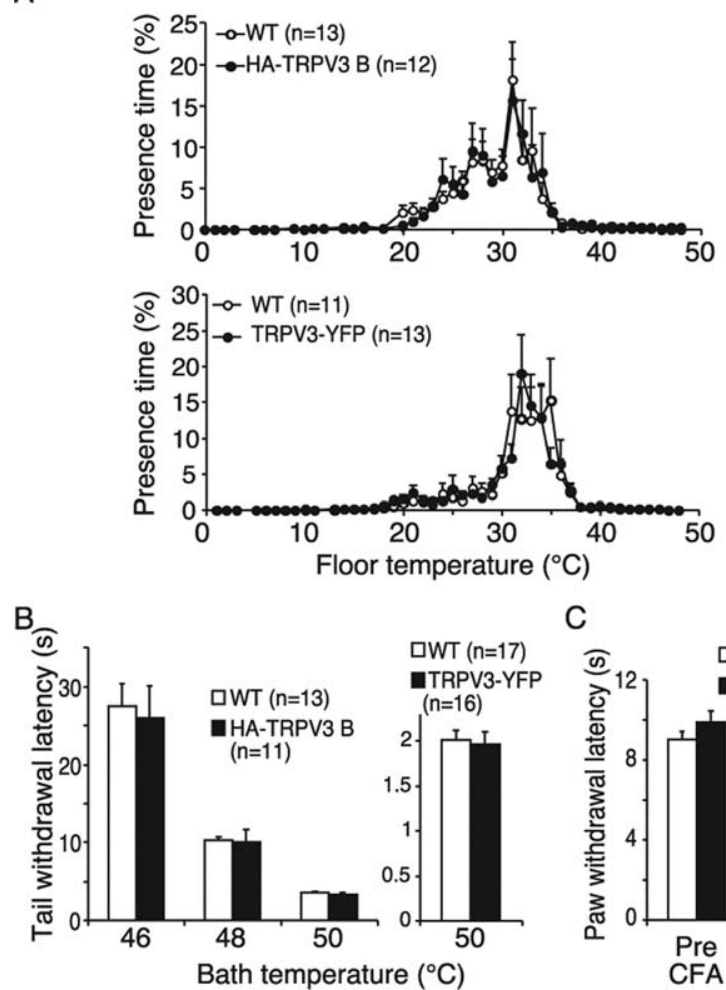

C

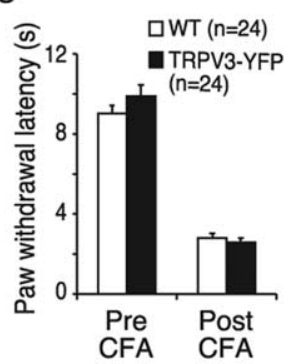

D
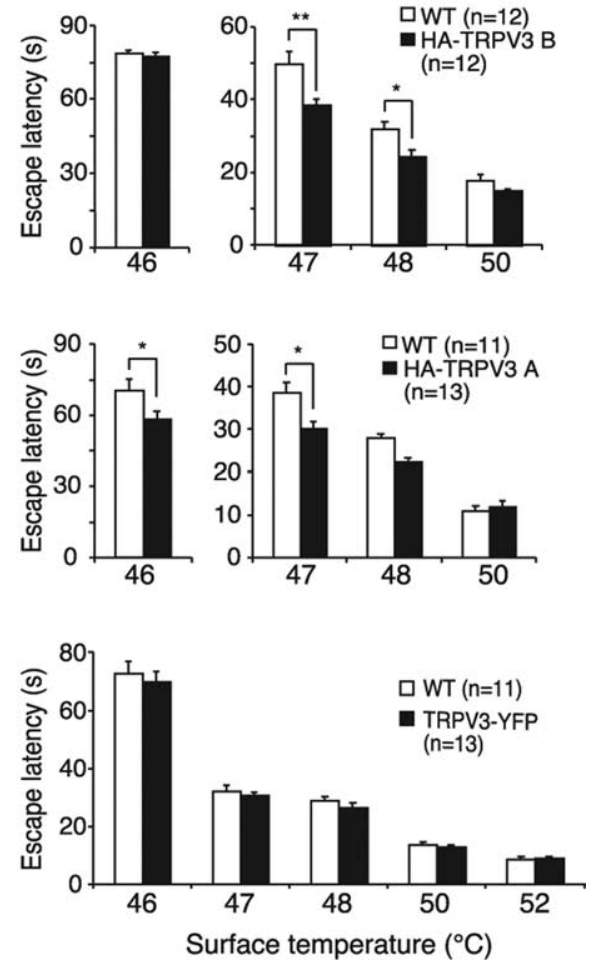

Figure 5. Temperature preference and pain behavior of wild-type and keratinocyte TRPV3 overexpressing mice. $\boldsymbol{A}$, Temperature preference behavior of HA-TRPV3 line B mice (top) and TRPV3-YFP mice (bottom) over $60-120$ min after placement in a temperature gradient ranging from 0 to $49^{\circ} \mathrm{C}$. Mean presence time at each temperature is illustrated. $\boldsymbol{B}$, Tail withdrawal behavior of HA-TRPV3 line B mice (top) and TRPV3-YFP mice (bottom) exposed to a heated water bath. C, Latency of paw withdrawal from radiant heat in wild-type and TRPV3-YFP mice before and $24 \mathrm{~h}$ after injection of CFA (15 $\mu$ l, intraplantar) into the ipsilateral hindpaw. D, Latency of HA-TRPV3 line B (top), HA-TRPV3 line A (middle) and TRPV3-YFP (bottom) mice to paw licking, biting, or shaking behavior upon placement on a hot plate at the indicated temperatures. In each graph, data shown are from a single cohort of $9-13$ mice per genotype. Two of three cohorts of HA-TRPV3 B mice, one of two cohorts of HA-TRPV3 A mice and two of two cohorts of TRPV3-YFP mice tested showed the presented response (see also supplemental Fig. S4C, available at www.jneurosci.org as supplemental material). Hot plate data were analyzed using Mann-Whitney $U$ test. ${ }^{* *} p<0.0001,{ }^{*} p<0.05$. Data are represented as mean \pm SEM. Numbers of mice $(n)$ are indicated in each panel.

across numerous mammalian species (Swanson et al., 2005; Gavva et al., 2007). To exclude the possibility that the reduced effect of JNJ-7203212 on hot plate latency in TRPV3-YFP transgenic mice is attributable to a differential impact of this compound on core body temperature, we directly compared its thermoregulatory effects between genotypes. Wild-type and TRPV3YFP transgenic mice were surgically implanted with telemetric body temperature probes. After 1 week of recovery, they were injected with JNJ-7203212 (40 mg/kg, i.p.) or vehicle (PBS). Whereas vehicle produced no significant changes in core body temperature, JNJ-7203212 evoked a transient hyperthermia that peaked at $\sim 30 \mathrm{~min}$ and subsided toward baseline within $180 \mathrm{~min}$ (Fig. 6D). This hyperthermic response was indistinguishable between wild-type and TRPV3-YFP transgenic mice. This result indicates that differences in hot plate latency between these two genotypes cannot be attributed to either differential body temperatures or a general diminution in JNJ-7203212 efficacy in TRPV3-YFP mice.

\section{Discussion}

Our findings that keratinocyte TRPV3 can mediate heat-evoked prostaglandin release and influence both acute nociception and hyperalgesia substantiate the notion that keratinocytes can contribute to sensory function. The responses of keratinocytes to TRPV3 stimuli in vitro were proportional to the TRPV3 expression level, with TRPV3-YFP keratinocytes exhibiting the largest responses to heat or 2APB. In the absence of TRPV1 antagonist, the in vivo TRPV3 transgenic thermal hypersensitivity phenotype was incompletely penetrant among cohorts, and not correlated with transgene expression level. There are several possible explanations for this apparent discrepancy. First, other downstream effectors and cell types necessary to translate increased channel functionality to behavior may have adapted to the lifelong excess of TRPV3 in some animals. Second, transgene mRNA expression was detected in the trigeminal ganglia of HA-TRPV3 mice, but not those of TRPV3-YFP mice. Although we could not resolve the cellular origin of this mRNA, it might result in increased TRPV3 expression in sensory neurons in HA-TRPV 3 mice. Third, behavioral differences between transgenic lines might be due to variations in the TRPV3 expression pattern within the skin epidermis, with TRPV3-YFP animals showing more uniform and robust basal epidermal overexpression, and HA-TRPV3 animals exhibiting strong but patchy overexpression in more superficial layers. These different patterns might stem from different transgene insertion sites. Alternatively, HA-TRPV3 and TRPV3-YFP proteins might differ in stability as keratinocytes migrate from basal to more superficial epidermal layers during differentiation. Differential function and expression of signaling molecules between keratinocytes in different epidermal layers is well recognized. For example, the antinociceptive modulator $\beta$-endorphin is differentially expressed across epidermal strata (Khodorova et al., 2003). In addition, the terminations of functionally distinct peptidergic and nonpeptidergic classes of small-diameter sensory neurons segregate to the stratum spinosum and the more superficial stratum granulosum, respectively (Zylka et al., 2005). Improved con- 
A
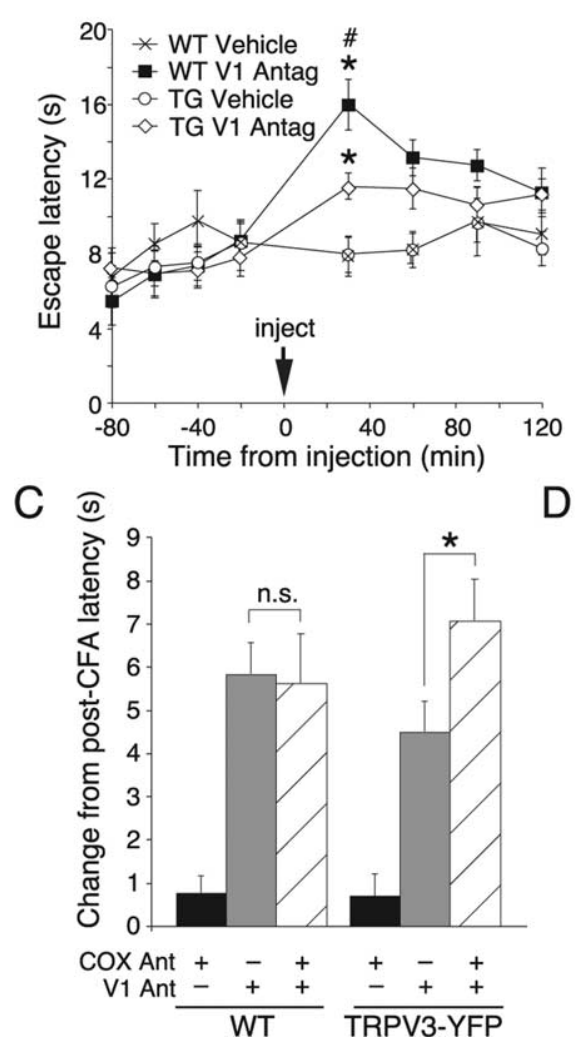

Figure 6. Changes in thermal pain behavior of TRPV3-YFP transgenic mice unmasked by pharmacological antagonism of TRPV1. $\boldsymbol{A}$, Hot plate $\left(52^{\circ} \mathrm{C}\right)$ latencies of wild-type and TRPV3-YFP transgenic mice before and after administration of the TRPV1 antagonist JNJ-7203212 (40 mg/kg, injected i.p. at arrow). Data were analyzed by ANOVA with Bonferroni post hoc comparisons; ${ }^{*} p<0.05$ antagonist versus vehicle; ${ }^{*} p<0.05$ wild type versus transgenic. $B$, Effects of cyclooxygenase antagonism. Wild-type and TRPV3-YFP transgenic mice were pretreated with the COX antagonist ibuprofen ( $40 \mathrm{mg} / \mathrm{kg}$, i.p.) or vehicle $15 \mathrm{~min}$ before injection of JNJ-7203212 or vehicle. Beginning 30 min after the final injection, hot plate latency was measured at 30 min intervals and 6 consecutive values averaged to calculate difference from the baseline (measured during the 90 min before ibuprofen injection). C, Effects of TRPV1 and COX antagonists on CFA-induced thermal hyperalgesia in wild-type and TRPV3-YFP transgenic mice. Immediately following the measurement of post-CFA paw withdrawal latency (Fig. 5C), TRPV3-YFP transgenic and wildtype mice were injected with ibuprofen (i.p., $40 \mathrm{mg} / \mathrm{kg}$ ) or vehicle, and 15 min later injected with JNJ-7203212 (40 mg/kg, i.p.) or vehicle. After an additional $30 \mathrm{~min}$, latency to escape from radiant paw heating was measured at 20 min intervals in the ipsilateral paw. The three latencies obtained between 50 and 90 min postinjection were averaged to calculate the change from the post-CFA baseline measured before ibuprofen injection. Note that ibuprofen increases withdrawal latency in TRPV3-YFP, but not wild-type mice treated with the TRPV1 antagonist. Planned comparisons of data in $\boldsymbol{B}$ and $\boldsymbol{C}$ were analyzed by Student's t test. ${ }^{*} p<0.05$; n.s., no significant difference ( $n=6-12$ per group). $\boldsymbol{D}$, Change in core body temperature in response to injection of JNJ-7203212 (40 $\mathrm{mg} / \mathrm{kg}$, i.p.) in wild-type (vehicle $n=4$, JNJ-7203212 $n=5$ ) versus TRPV3-YFP (JNJ-7203212; $n=8$ ) mice.

trol of layer-specific TRPV3 overexpression using transgene insulators or other epidermal promoters might help to clarify this issue. Finally, one cannot exclude the possibility that epitope tagging of the TRPV3 construct affected proper trafficking or coupling to other proteins, although neither tag appeared to interfere with either ion channel function or $\mathrm{PGE}_{2}$ release in vitro.

In contrast to their apparently normal thermal nociception in the absence of pharmacological agents, TRPV3-YFP transgenic mice (the highest TRPV3 expressing line) consistently exhibited greater thermal nociception than wild-type mice upon pharmacological inhibition of TRPV1. This effect is apparently not attributable to changes in TRPV1 expression in the transgenic mice. These data suggest that keratinocyte TRPV3 channels facilitate heat-evoked activation of nociceptive signaling pathways, but that this effect is masked by the activity of TRPV1. Overlap between the activation temperatures of TRPV3 (Peier et al., 2002; Smith et al., 2002; Xu et al., 2002) TRPV1 (Tominaga et al., 1998), and TRPV4 (Guler et al., 2002; Watanabe et al., 2002), as well as the relatively modest thermal nociceptive phenotypes of individual TRPV channel knockouts (Caterina et al., 2000; Davis et al., 2000; Liedtke and Friedman, 2003; Suzuki et al., 2003; Lee et al., 2005; Moqrich et al., 2005) support the notion of functional redundancy between these molecules. Redundancy is likely further expanded by the expression of these thermosensitive molecules in multiple cell types. Such overlap in function may be evolutionarily advantageous, as encoding and signaling of high temperatures that cause tissue damage is essential for survival.

Surprisingly, 2APB did not potentiate heat-evoked $\mathrm{PGE}_{2}$ release from wild-type cells, as it did in transgenic cells. One interpretation of this finding is that endogenous TRPV3, when expressed at normal levels, is not a major contributor to heatevoked $\mathrm{PGE}_{2}$ release from keratinocytes and that additional, TRPV3-independent mechanisms exist for such release. However, given the pleiotropic actions of $2 \mathrm{APB}$ (Bootman et al., 2002), we cannot exclude potential inhibitory effects of this compound on targets downstream of endogenous TRPV3 signaling. Alternatively, our findings might reflect low endogenous TRPV3 expression levels under our culture conditions. In wild-type keratinocytes, TRPV3-like currents evoked by heat were not readily detected unless $2 \mathrm{APB}$ was coapplied, consistent with our previous observations (Chung et al., 2004b). Other investigators have reported more frequent TRPV3-like heat-evoked currents in keratinocyte cultures (Moqrich et al., 2005). Although our conclusions are derived largely from TRPV3 gain-of-function conditions, overexpression of keratinocyte TRPV3 is not a situation unique to our transgenic model. Human patients experiencing cutaneous pain after breast surgery show an upregulation of both TRPV3 and TRPV4 in keratinocytes of affected skin that is most evident in the basal epidermis (Gopinath et al., 2005).

Our data also suggest that $\mathrm{PGE}_{2}$ is at least one signal by which keratinocyte TRPV3 channels can communicate with cutaneous sensory neurons. The association between $\mathrm{PGE}_{2}$, sensory transduction, and TRP channels is consistent with the established role of $\mathrm{PGE}_{2}$ as a pronociceptive mediator (Cesare and McNaughton, 1997; Bley et al., 1998). EP1, EP3 and EP4 receptors are found on primary sensory neurons (Sugimoto et al., 1994; Oida et al., 1995; Southall and Vasko, 2001; Moriyama et al., 2005). One consequence of $\mathrm{PGE}_{2}$ action is sensitization of neuronal TRPV1 via EP1 or EP4 receptors, and TRPV1 has been found to be a major contributor to $\mathrm{PGE}_{2}$-induced inflammatory heat hyperalgesia in mice (Moriyama et al., 2005). Nevertheless, other mechanisms of $\mathrm{PGE}_{2}$-induced hypersensitivity have been reported. $\mathrm{PGE}_{2}$ can modulate neuronal TTX-resistant sodium currents (England et al., 1996; Gold et al., 1996) and suppress voltage-activated out- 
ward potassium currents (Nicol et al., 1997). Furthermore, $\mathrm{PGA}_{2}$, a $\mathrm{PGE}_{2}$ derivative, can evoke pain by acting at TRPA1 on nociceptive neurons (Materazzi et al., 2008). Our results with the TRPV1 antagonist suggest that, at least in the context of TRPV3 overexpression, the downstream effects of keratinocyte TRPV3stimulated release of $\mathrm{PGE}_{2}$ are likely mediated by TRPV1independent mechanisms.

The effects of TRPV3-stimulated $\mathrm{PGE}_{2}$ may not be limited to pain modulation, since prostaglandins in the skin have been implicated in functions such as keratinocyte differentiation, wound healing, inflammation and tumorigenesis (Lee et al., 2003). It is possible, for example, that $\mathrm{PGE}_{2}$ contributes to the hair cycle defects and dermatitis observed in Nh mice and WBN/Kob-Ht rats (Asakawa et al., 2006; Imura et al., 2007). These lines harbor naturally occurring point mutations in the TRPV3 gene that render the channel constitutively active and hypersensitive to TRPV3 agonists (Asakawa et al., 2006; Xiao et al., 2008). A lack of constitutive TRPV3 channel activity in our transgenic mice might explain the absence of alopecia, although more extensive analyses will be required to totally exclude more subtle hair cycle defects. Given the results of our study, it would also be interesting to evaluate thermosensation and thermal nociception in $\mathrm{Nh}$ mice and WBN/Kob-Ht rats. Conversely, it is likely that mediators other than $\mathrm{PGE}_{2}$ are involved in modulating pain sensitivity upon keratinocyte TRPV3 activation. Small molecules that have been shown to be involved in sensory transduction and released from epithelial cells, such as ATP (Cockayne et al., 2000; Birder et al., 2002; Koizumi et al., 2004; Birder et al., 2007; Roper, 2007) and serotonin (Roper, 2007) are plausible candidates. In addition, one TRPV3 agonist, eugenol, has been reported to trigger the release of interleukin- $1 \alpha$ from oral mucosal epithelial cells (Xu et al., 2006), although involvement of TRPV3 in such release was not definitively established. In another recent study (Yoshioka et al., 2008), the transgenic overexpression of the hypersensitized TRPV3 mutant found in Nh mice was reported to result in enhanced NGF release from epidermal sheets at $33^{\circ} \mathrm{C}$, but normal release at $37^{\circ} \mathrm{C}$. Since NGF can also sensitize sensory afferents, it will be interesting to determine whether overexpressed wild-type TRPV3 also enhances release of this mediator.

The anatomical basis of communication between keratinocytes and sensory neurons is poorly understood. Despite the close juxtaposition between the membranes of keratinocytes and sensory nerve endings, no synapse-like structures have been identified at these points of proximity. Our present results showing that $\mathrm{PGE}_{2}$ is released upon keratinocyte TRPV3 activation may offer a resolution to this dilemma. $\mathrm{PGE}_{2}$, like many other lipid mediators, is not packaged in vesicles, but is instead synthesized on demand. Acute calcium influx through TRPV3 channels likely activates calcium-sensitive isoforms of phospholipase $A_{2}$, which in turn provide arachidonic acid as a substrate for COX, thereby initiating the prostaglandin synthesis cascade (Smith et al., 2000). Once synthesized, $\mathrm{PGE}_{2}$ is released from cells via plasma membrane transporters (Funk, 2001). Hence, communication between keratinocytes and sensory neurons via $\mathrm{PGE}_{2}$ release and action would not require a classical synapse.

Together, our findings reveal a mechanism by which TRPV3 expressed in skin keratinocytes can participate in modulating thermal nociception, hence broadening our understanding of sensory transduction. Our study might also have therapeutic implications with respect to the efficacy of TRPV1-selective antagonists, and their coadministration with COX inhibitors, particularly in disease states where TRPV3 or other heat-gated channels are upregulated or sensitized in the skin.

\section{References}

Albers KM, Davis BM (2007) The skin as a neurotrophic organ. Neuroscientist 13:371-382.

Asakawa M, Yoshioka T, Matsutani T, Hikita I, Suzuki M, Oshima I, Tsukahara K, Arimura A, Horikawa T, Hirasawa T, Sakata T (2006) Association of a mutation in TRPV3 with defective hair growth in rodents. J Invest Dermatol 126:2664-2672.

Birder L, Kullmann FA, Lee H, Barrick S, de Groat W, Kanai A, Caterina M (2007) Activation of urothelial transient receptor potential vanilloid 4 by 4alpha-phorbol 12,13-didecanoate contributes to altered bladder reflexes in the rat. J Pharmacol Exp Ther 323:227-235.

Birder LA, Nakamura Y, Kiss S, Nealen ML, Barrick S, Kanai AJ, Wang E, Ruiz G, De Groat WC, Apodaca G, Watkins S, Caterina MJ (2002) Altered urinary bladder function in mice lacking the vanilloid receptor TRPV1. Nat Neurosci 5:856-860.

Bley KR, Hunter JC, Eglen RM, Smith JA (1998) The role of IP prostanoid receptors in inflammatory pain. Trends Pharmacol Sci 19:141-147.

Bootman MD, Collins TJ, Mackenzie L, Roderick HL, Berridge MJ, Peppiatt CM (2002) 2-aminoethoxydiphenyl borate (2-APB) is a reliable blocker of store-operated $\mathrm{Ca} 2+$ entry but an inconsistent inhibitor of InsP3induced $\mathrm{Ca} 2+$ release. FASEB J 16:1145-1150.

Caterina MJ, Leffler A, Malmberg AB, Martin WJ, Trafton J, Petersen-Zeitz KR, Koltzenburg M, Basbaum AI, Julius D (2000) Impaired nociception and pain sensation in mice lacking the capsaicin receptor. Science 288:306-313.

Cesare P, McNaughton P (1997) Peripheral pain mechanisms. Curr Opin Neurobiol 7:493-499.

Chung MK, Lee H, Caterina MJ (2003) Warm temperatures activate TRPV4 in mouse 308 keratinocytes. J Biol Chem 278:32037-32046.

Chung MK, Lee H, Mizuno A, Suzuki M, Caterina MJ (2004a) TRPV3 and TRPV4 mediate warmth-evoked currents in primary mouse keratinocytes. J Biol Chem 279:21569-21575.

Chung MK, Lee H, Mizuno A, Suzuki M, Caterina MJ (2004b) 2-aminonethoxydiphenyl borate activates and sensitizes the heat-gated ion channel, TRPV3. J Neurosci 24:5177-5182.

Chung MK, Güler AD, Caterina MJ (2005) Biphasic currents evoked by chemical or thermal activation of the heat-gated ion channel, TRPV3. J Biol Chem 280:15928-15941.

Cockayne DA, Hamilton SG, Zhu QM, Dunn PM, Zhong Y, Novakovic S, Malmberg AB, Cain G, Berson A, Kassotakis L, Hedley L, Lachnit WG, Burnstock G, McMahon SB, Ford AP (2000) Urinary bladder hyporeflexia and reduced pain-related behaviour in P2X3- deficient mice. Nature 407:1011-1015.

Davis JB, Gray J, Gunthorpe MJ, Hatcher JP, Davey PT, Overend P, Harries MH, Latcham J, Clapham C, Atkinson K, Hughes SA, Rance K, Grau E, Harper AJ, Pugh PL, Rogers DC, Bingham S, Randall A, Sheardown SA (2000) Vanilloid receptor-1 is essential for inflammatory thermal hyperalgesia. Nature 405:183-187.

England S, Bevan S, Docherty RJ (1996) PGE2 modulates the tetrodotoxinresistant sodium current in neonatal rat dorsal root ganglion neurones via the cyclic AMP-protein kinase A cascade. J Physiol 495:429-440.

Ferreira SH, Nakamura M, de Abreu Castro MS (1978) The hyperalgesic effects of prostacyclin and prostaglandin E2. Prostaglandins 16:31-37.

Funk CD (2001) Prostaglandins and leukotrienes: advances in eicosanoid biology. Science 294:1871-1875.

García-Martinez C, Humet M, Planells-Cases R, Gomis A, Caprini M, Viana F, De La Pena E, Sanchez-Baeza F, Carbonell T, De Felipe C, Pérez-Paya E, Belmonte C, Messeguer A, Ferrer-Montiel A (2002) Attenuation of thermal nociception and hyperalgesia by VR1 blockers. Proc Natl Acad Sci U S A 99:2374-2379.

Gavva NR, Tamir R, Qu Y, Klionsky L, Zhang TJ, Immke D, Wang J, Zhu D, Vanderah TW, Porreca F, Doherty EM, Norman MH, Wild KD, Bannon AW, Louis JC, Treanor JJ (2005) AMG 9810 [(E)-3-(4-t-Butylphenyl)$N$-(2,3-dihydrobenzo[b][1,4] dioxin-6-yl)acrylamide], a novel vanilloid receptor 1 (TRPV1) antagonist with antihyperalgesic properties. J Pharmacol Exp Ther 313:474-484.

Gavva NR, Bannon AW, Surapaneni S, Hovland DN Jr, Lehto SG, Gore A, Juan T, Deng H, Han B, Klionsky L, Kuang R, Le A, Tamir R, Wang J, Youngblood B, Zhu D, Norman MH, Magal E, Treanor JJ, Louis JC (2007) The vanilloid receptor TRPV1 is tonically activated in vivo and involved in body temperature regulation. J Neurosci 27:3366-3374.

Ghilardi JR, Röhrich H, Lindsay TH, Sevcik MA, Schwei MJ, Kubota K, Hal- 
vorson KG, Poblete J, Chaplan SR, Dubin AE, Carruthers NI, Swanson D, Kuskowski M, Flores CM, Julius D, Mantyh PW (2005) Selective blockade of the capsaicin receptor TRPV1 attenuates bone cancer pain. J Neurosci 25:3126-3131.

Gold MS, Reichling DB, Shuster MJ, Levine JD (1996) Hyperalgesic agents increase a tetrodotoxin-resistant $\mathrm{Na}+$ current in nociceptors. Proc Natl Acad Sci U S A 93:1108-1112.

Gopinath P, Wan E, Holdcroft A, Facer P, Davis JB, Smith GD, Bountra C, Anand P (2005) Increased capsaicin receptor TRPV1 in skin nerve fibres and related vanilloid receptors TRPV3 and TRPV4 in keratinocytes in human breast pain. BMC Womens Health 5:2.

Güler AD, Lee H, Iida T, Shimizu I, Tominaga M, Caterina M (2002) Heatevoked activation of the ion channel, TRPV4. J Neurosci 22:6408-6414.

Hilliges M, Wang L, Johansson O (1995) Ultrastructural evidence for nerve fibers within all vital layers of the human epidermis. J Invest Dermatol 104:134-137.

Hu HZ, Gu Q, Wang C, Colton CK, Tang J, Kinoshita-Kawada M, Lee LY, Wood JD, Zhu MX (2004) 2-aminoethoxydiphenyl borate is a common activator of TRPV1, TRPV2, and TRPV3. J Biol Chem 279:35741-35748.

Hu HZ, Xiao R, Wang C, Gao N, Colton CK, Wood JD, Zhu MX (2006) Potentiation of TRPV3 channel function by unsaturated fatty acids. J Cell Physiol 208:201-212.

Imura K, Yoshioka T, Hikita I, Tsukahara K, Hirasawa T, Higashino K, Gahara Y, Arimura A, Sakata T (2007) Influence of TRPV3 mutation on hair growth cycle in mice. Biochem Biophys Res Commun 363:479-483.

Khodorova A, Navarro B, Jouaville LS, Murphy JE, Rice FL, Mazurkiewicz JE, Long-Woodward D, Stoffel M, Strichartz GR, Yukhananov R, Davar G (2003) Endothelin-B receptor activation triggers an endogenous analgesic cascade at sites of peripheral injury. Nat Med 9:1055-1061.

Koizumi S, Fujishita K, Inoue K, Shigemoto-Mogami Y, Tsuda M, Inoue K (2004) $\mathrm{Ca} 2+$ waves in keratinocytes are transmitted to sensory neurons: the involvement of extracellular ATP and P2Y2 receptor activation. Biochem J 380:329-338.

Lee H, Iida T, Mizuno A, Suzuki M, Caterina MJ (2005) Altered thermal selection behavior in mice lacking transient receptor potential vanilloid 4 . J Neurosci 25:1304-1310.

Lee JL, Mukhtar H, Bickers DR, Kopelovich L, Athar M (2003) Cyclooxygenases in the skin: pharmacological and toxicological implications. Toxicol Appl Pharmacol 192:294-306.

Liedtke W, Friedman JM (2003) Abnormal osmotic regulation in trpv4-/mice. Proc Natl Acad Sci U S A 100:13698-13703.

Malin SA, Molliver DC, Koerber HR, Cornuet P, Frye R, Albers KM, Davis BM (2006) Glial cell line-derived neurotrophic factor family members sensitize nociceptors in vitro and produce thermal hyperalgesia in vivo. J Neurosci 26:8588-8599.

Materazzi S, Nassini R, Andrè E, Campi B, Amadesi S, Trevisani M, Bunnett NW, Patacchini R, Geppetti P (2008) Cox-dependent fatty acid metabolites cause pain through activation of the irritant receptor TRPA1. Proc Natl Acad Sci U S A 105:12045-12050.

McGaraughty S, Chu KL, Faltynek CR, Jarvis MF (2006) Systemic and sitespecific effects of A-425619, a selective TRPV1 receptor antagonist, on wide dynamic range neurons in CFA-treated and uninjured rats. J Neurophysiol 95:18-25.

Moqrich A, Hwang SW, Earley TJ, Petrus MJ, Murray AN, Spencer KS, Andahazy M, Story GM, Patapoutian A (2005) Impaired thermosensation in mice lacking TRPV3, a heat and camphor sensor in the skin. Science 307:1468-1472.

Moriyama T, Higashi T, Togashi K, Iida T, Segi E, Sugimoto Y, Tominaga T, Narumiya S, Tominaga M (2005) Sensitization of TRPV1 by EP1 and IP reveals peripheral nociceptive mechanism of prostaglandins. Mol Pain $1: 3$.

Nicol GD, Vasko MR, Evans AR (1997) Prostaglandins suppress an outward potassium current in embryonic rat sensory neurons. J Neurophysiol $77: 167-176$.

Oida H, Namba T, Sugimoto Y, Ushikubi F, Ohishi H, Ichikawa A, Narumiya
S (1995) In situ hybridization studies of prostacyclin receptor mRNA expression in various mouse organs. Br J Pharmacol 116:2828-2837.

Paladini RD, Coulombe PA (1998) Directed expression of keratin 16 to the progenitor basal cells of transgenic mouse skin delays skin maturation. J Cell Biol 142:1035-1051.

Peier AM, Reeve AJ, Andersson DA, Moqrich A, Earley TJ, Hergarden AC, Story GM, Colley S, Hogenesch JB, McIntyre P, Bevan S, Patapoutian A (2002) A heat-sensitive TRP channel expressed in keratinocytes. Science 296:2046-2049.

Roper SD (2007) Signal transduction and information processing in mammalian taste buds. Pflugers Arch 454:759-776.

Smith GD, Gunthorpe MJ, Kelsell RE, Hayes PD, Reilly P, Facer P, Wright JE, Jerman JC, Walhin JP, Ooi L, Egerton J, Charles KJ, Smart D, Randall AD, Anand P, Davis JB (2002) TRPV3 is a temperature-sensitive vanilloid receptor-like protein. Nature 418:186-190.

Smith WL, DeWitt DL, Garavito RM (2000) Cyclooxygenases: structural, cellular, and molecular biology. Annu Rev Biochem 69:145-182.

Southall MD, Vasko MR (2001) Prostaglandin receptor subtypes, EP3C and EP4, mediate the prostaglandin E2-induced cAMP production and sensitization of sensory neurons. J Biol Chem 276:16083-16091.

Southall MD, Li T, Gharibova LS, Pei Y, Nicol GD, Travers JB (2003) Activation of epidermal vanilloid receptor-1 induces release of proinflammatory mediators in human keratinocytes. J Pharmacol Exp Ther 304:217-222.

Sugimoto Y, Shigemoto R, Namba T, Negishi M, Mizuno N, Narumiya S, Ichikawa A (1994) Distribution of the messenger RNA for the prostaglandin E receptor subtype EP3 in the mouse nervous system. Neuroscience 62:919-928.

Suzuki M, Mizuno A, Kodaira K, Imai M (2003) Impaired pressure sensation in mice lacking TRPV4. J Biol Chem 278:22664-22668.

Swanson DM, Dubin AE, Shah C, Nasser N, Chang L, Dax SL, Jetter M, Breitenbucher JG, Liu C, Mazur C, Lord B, Gonzales L, Hoey K, Rizzolio M, Bogenstaetter M, Codd EE, Lee DH, Zhang SP, Chaplan SR, Carruthers NI (2005) Identification and biological evaluation of 4-(3-trifluoromethylpyridin-2yl)piperazine-1-carboxylic acid (5-trifluoromethylpyridin-2-yl)amide, a high affinity TRPV1 (VR1) vanilloid receptor antagonist. J Med Chem 48:1857-1872.

Taiwo YO, Levine JD (1989a) Contribution of guanine nucleotide regulatory proteins to prostaglandin hyperalgesia in the rat. Brain Res 492:400-403.

Taiwo YO, Levine JD (1989b) Prostaglandin effects after elimination of indirect hyperalgesic mechanisms in the skin of the rat. Brain Res 492:397-399.

Tominaga M, Caterina MJ, Malmberg AB, Rosen TA, Gilbert H, Skinner K, Raumann BE, Basbaum AI, Julius D (1998) The cloned capsaicin receptor integrates multiple pain-producing stimuli. Neuron 21:531-543.

Watanabe H, Vriens J, Suh SH, Benham CD, Droogmans G, Nilius B (2002) Heat-evoked activation of TRPV4 channels in an HEK293 cell expression system and in native mouse aorta endothelial cells. J Biol Chem 277:47044-47051.

Xiao R, Tian J, Tang J, Zhu MX (2008) The TRPV3 mutation associated with the hairless phenotype in rodents is constitutively active. Cell Calcium 43:334-343.

Xu H, Ramsey IS, Kotecha SA, Moran MM, Chong JA, Lawson D, Ge P, Lilly J, Silos-Santiago I, Xie Y, DiStefano PS, Curtis R, Clapham DE (2002) TRPV3 is a calcium-permeable temperature-sensitive cation channel. Nature 418:181-186.

Xu H, Delling M, Jun JC, Clapham DE (2006) Oregano, thyme and clovederived flavors and skin sensitizers activate specific TRP channels. Nat Neurosci 9:628-635.

Yoshioka T, Imura K, Asakawa M, Suzuki M, Oshima I, Hirasawa T, Sakata T, Horikawa T, Arimura A (2008) Impact of the Gly573Ser substitution in TRPV3 on the development of allergic and pruritic dermatitis in mice. J Invest Dermatol. Advance online publication. Retreived August 28, 2008. doi: 10.1038/jid.2008.245

Zylka MJ, Rice FL, Anderson DJ (2005) Topographically distinct epidermal nociceptive circuits revealed by axonal tracers targeted to Mrgprd. Neuron 45:17-25. 